\title{
(Des)investimento na formação docente em Educação Física: perfis e trajetórias de estudantes de licenciatura
}

\section{RESUMO}

Este estudo visa caracterizar e analisar o perfil e investimentos de professores em formação na licenciatura em Educação Física. $\mathrm{O}$ estudo é qualitativo de caráter exploratório. $\mathrm{O}$ instrumento para a obtenção dos dados foi a entrevista semiestruturada. Para tratamento dos dados, foi utilizada a técnica de análise de conteúdo. Como resultado foram encontradas três categorias referente a perfis de professores em formação, são elas: "Ser professor! ", em que os alunos demostraram compreensão ampla das finalidades da Educação Física escolar e perspectivam atuar na área; "Licenciando ao acaso", em referência aos estudantes que ao ingressar não compreendiam a distinção das habilitações na formação ou não se identificavam com o curso, mas, ao longo da formação, têm construído uma identificação e pretendem atuar; por fim, o perfil "Desinvestimento na trajetória formativa docente", que revela uma falta de identificação com a área de formação, que repercute em desinvestimento ao longo da trajetória de formação docente.

PALAVRAS-CHAVE: Formação Profissional; Docente; Educação física
Graduanda em Licenciatura em Educação

Física

Universidade Federal de Viçosa - UFV,

Departamento de Educação Física

Viçosa, Minas Gerais, Brasil

clarissescaetano@gmail.com

https://orcid.org/0000-0002-0533-0282

\section{Doiara Silva dos Santos}

Doutorado em Educação Física

Universidade Federal de Viçosa - UFV,

Departamento Educação Física

Viçosa, Minas Gerais, Brasil santosdoiara@ufv.br

https://orcid.org/0000-0002-4718-7226 
(Dis) investment in teacher formation in Physical Education: profiles and trajectories of undergraduate students

\begin{abstract}
This study aims to characterize the profile and investment of undergraduate students in Physical Education. The study is qualitative and exploratory, and the instrument for obtaining data was the semi-structured interview. For data treatment it was performed content analysis. As a result, three categories were found, namely: "Being a teacher!", in which students showed broad understanding of the area and demonstrated that they intend working in schools; "Randomly Licensing", in which students did not have an understanding of the field at the time of entry, but throughout the training they built an identification and intend to work in the area; finally, the profile "Unintentional in the formative trajectory" that reveals a distance from the area and disinvestment in teacher training.
\end{abstract}

KEYWORDS: Professional qualification; Teacher; Physical education

(Des) inversión en la formación del profesorado en Educación Física: perfiles y trayectorias de estudiantes de pregrado

\title{
RESUMEN
}

Este estúdio tiene como objetivo caracterizar el perfil y la inversión de docentes en la formación en cursos de pregrado. El estudio es cualitativo y exploratorio. El instrumento para la obtención de los datos fue la entrevista semiestructurada. Para el tratamiento de los datos se utilizó la técnica de análisis de contenido. Como resultado, se encontraron tres categorías en cuanto a los perfiles de los docentes en formación, son: “iSer docente! ”En esto los estudiantes mostraron comprensión y esperan trabajar en el área; "Licenciamiento al azar", en referencia a los estudiantes que al ingresar no entendieron la distinción de calificaciones o no se identificaron con el curso, pero a lo largo de la formación construyeron una identificación y pretenden actuar; finalmente, "Desintencionalidad en la trayectoria de formación docente" revela un alejamiento del área de formación, revelando una desinversión a lo largo de la trayectoria de formación docente.

PALABRAS-CLAVE: Formación profesional; Profesor; Educación física 


\section{INTRODUÇÃO}

A Educação Física tem duas possibilidades de formação: o bacharelado e a licenciatura. Em linhas gerais, a licenciatura tem como foco a preparação para a docência no ambiente escolar. $\mathrm{O}$ bacharelado, por sua vez, é voltado para outros campos de atuação que perpassam o mercado fitness, formação e treinamento esportivo, dentre outros (CONSELHO NACIONAL DE EDUCAÇÃO, 2004). ${ }^{1}$

Desde a criação do bacharelado na década de 1980, a forma de ingresso na formação em Educação Física passou por alterações entre a Área Básica de Ingresso (ABI) - em que, somente após concluir um ciclo básico, o estudante faz a escolha pela modalidade de Bacharelado ou Licenciatura - e o ingresso diretamente na habilitação específica ${ }^{2}$. Este estudo dedica-se a investigar formação de professores cujo ingresso se deu na habilitação específica para a licenciatura na Universidade Federal de Viçosa.

Uma questão a considerar sobre o ingresso no curso de uma Instituição de Ensino Superior (IES) pública é a nota obtida no Exame Nacional do Ensino Médio (ENEM). No modelo em vigor, o candidato a uma vaga no curso de formação universitária tem conhecimento da média alcançada no ENEM antes de fazer a sua inscrição no Sistema Seleção Unificada (SISU). Após a inscrição, o candidato pode acompanhar sua classificação no curso escolhido, com o acesso às notas de cortes de todos os cursos disponíveis. Dessa forma, o candidato pode, como forma de garantir o seu ingresso em uma universidade, trocar suas opções de curso buscando uma área de formação para a qual a sua nota no ENEM seja satisfatória para a obtenção da vaga na IES pretendida.

Esse processo significa que nem sempre o candidato ingressa num curso por ele almejado, ou seja, estudantes podem acabar por optar por uma lógica de conveniência para o ingresso no Ensino Superior, pelo significado social de ser estudante universitário ou mera experimentação. As implicações disso são muitas, pois, podem ocorrer, com frequência, frustações com a área de formação que o estudante ingressa, falta de identificação com os conhecimentos do currículo e área de formação, abandono do curso e, no caso de permanência na graduação, uma qualificação sem investimentos por parte do estudante, o que pode resultar em precária futura atuação profissional.

Parte-se do pressuposto de que para dar sentido à sua futura atuação profissional, é preciso que, desde a formação inicial, o estudante da licenciatura invista na busca e aprendizado de

\footnotetext{
${ }_{1}$ A discussão sobre o modelo binomial de formação em Educação Física é acompanhada, historicamente, por tensionamentos que repercutem nas instituições e órgãos como, por exemplo, o Conselho Federal de Educação Física, o Conselho Nacional de Educação e no campo acadêmico. São fatores que implicam em questões de legitimação social e legal. Para mais informações, ver Benites; Neto e Hunger (2008).

${ }^{2}$ A Forma de ingresso ABI não estava em vigor na Universidade Federal de Viçosa na data de conclusão desse estudo, porém, segundo a Resolução Conselho Nacional de Educação/CES n ${ }^{\circ}$ 6, de 18 de dezembro de 2018, a forma de ingresso $\mathrm{ABI}$ voltará a vigorar até 2 anos a partir da data da publicação dessa resolução.
} 
conhecimentos que possam contribuir para constituir saberes para a prática pedagógica em Educação Física no ambiente escolar. Outro pressuposto é o de que, quando há um distanciamento ou falta de investimentos voltados para tornar-se professor de Educação Física escolar (desinvestimento), incorre-se no risco de que, por força das oportunidades de campo de atuação quanto à empregabilidade, alguns professores que venham a atuar na escola tenham uma compreensão limitada do trabalho docente e da importância de se dedicar a conhecimentos que contribuam para a construção dos saberes pedagógicos em seu cotidiano.

Nesse sentido, buscando contribuir para a ampliação das problematizações sobre a formação inicial em Educação Física, este trabalho se apropria de perspectivas sobre inovação e desinvestimento pedagógico, que têm sido utilizadas para discutir a prática pedagógica de professores em atuação (MACHADO et al, 2010; FARIAS et al., 2010). Neste estudo, realiza-se o exercício teórico-analítico de transpor estas perspectivas de investimento ou inovação, bem como de desinvestimento, para o momento anterior à prática pedagógica do profissional que é a formação. Machado et al. (2010, p.132), assim apresentam a caracterização do desinvestimento:

Não como uma fase, mas sim como um estado, o que nos distancia de uma compreensão do fenômeno como algo dotado de certa cronologia ou linearidade. No caso específico da EF, o desinvestimento, por nós adjetivado de pedagógico, corresponderia àqueles casos em que os professores de $\mathrm{EF}$ escolar permanecem em seus postos de trabalho, mas abandonam o compromisso com a qualidade do trabalho docente (MACHADO et al. 2010, p. 132).

Ao transpor essa discussão para a formação inicial, falamos em desinvestimento na formação como a falta de compromisso com a qualidade da formação por parte de discentes. Ao passo que o investimento é possível ser caracterizado como forma de buscar a melhor qualificação possível dentro do objetivo almejado de tornar-se professor, sendo esta uma tarefa constante, que simboliza comprometimento, estudo e apropriação de conhecimentos relacionados ao trabalho docente. Outro termo utilizado para caracterizar esse investimento, sobretudo quando o professor já está em atuação, é inovação pedagógica que, embora Faria et al. (2010, p. 12) mencionem a dificuldade de conceituar esse termo, entendem que uma prática inovadora nas aulas de Educação Física se caracteriza quando o professor: "Mesmo diante das dificuldades, aí presentes, conseguem construir, por meio de (re)significações e contextualizações das teorias pedagógicas, uma prática pedagógica inovadora, capaz de romper com a ideia tradicional de ensino."

Assim, ao pensarmos a ideia de investimento/inovação dentro da graduação, estamos pensando na busca do professor em formação por conhecimentos teórico-científicos que fundamentam e instrumentalizam sua futura prática docente, com a apropriação do currículo e suas 
possibilidades, mas, também buscando complementar sua formação para além do prescrito na matriz curricular.

Tendo em vista que o professor cumpre um papel social importante, contribuindo para a formação humana dentro de um projeto de sociedade (SAVIANI, 2009), estudar perfis de estudantes do curso de licenciatura oferece subsídios para discutir caminhos formativos de futuros professores e suas dinâmicas. O pouco investimento na formação, a falta de compreensão do próprio currículo, bem como a ausência de identificação com a futura área de atuação em um momento tão crucial na constituição dos saberes do professor, pode ter sérias implicações para a prática pedagógica em Educação Física escolar quanto à sua contribuição para a formação humana e cidadã no sistema educacional como um todo, nos diversos níveis de ensino.

Assim, o foco desta investigação está em caracterizar perfis de discentes de Licenciatura em Educação Física quanto aos investimentos e desinvestimentos na trajetória de formação inicial na licenciatura em Educação Física na Universidade Federal de Viçosa (UFV). Em específico, buscouse: identificar motivações e significações atribuídas à escolha da Licenciatura em Educação Física como área de estudos no Ensino Superior; mapear e analisar investimentos e desinvestimentos na formação em Licenciatura em Educação Física; identificar e discutir perspectivas de atuação de licenciandos em Educação Física na UFV.

\section{METODOLOGIA}

Este estudo é caracterizado, de acordo com sua problemática, como de natureza qualitativa, ou seja, os dados têm na realidade particular a principal forma direta para encontrá-los (ZANATTA; COSTA, 2012). Esta investigação sobre a formação docente tem caráter exploratório. $O$ estudo foi submetido e aprovado como projeto de pesquisa ao Comitê de Ética e Pesquisa da Universidade Federal Viçosa em 2019, sob o número de parecer 3.797.206. Os procedimentos éticos foram realizados de acordo com a resolução 466/2012 do de Conselho Nacional de Saúde. Também se reafirma a conformidade com a Resolução CNS nº 510 de 2016 (Normas aplicáveis a pesquisas em Ciências Humanas e Sociais).

A composição dos sujeitos participantes foi intencional, com alunos a partir do $5^{\circ}$ período do curso de Licenciatura em Educação Física da Universidade Federal de Viçosa. Esse período foi o escolhido pelo fato de que o discente nesta fase apresenta, regularmente, uma porcentagem razoável do curso concluída e, também, cursou e teve contato, conforme organização curricular da instituição, parte considerável das disciplinas didático-pedagógicas (incluindo práticas de ensino e estágio supervisionado) previstas na instituição em questão. Cada estudante que aceitou participar 
da pesquisa no prazo estipulado no cronograma, assinou o Termo de Consentimento Livre e Esclarecido (TCLE), em que consta que a sua participação consiste em responder a uma entrevista.

A técnica de coleta de dados da pesquisa foi uma entrevista do tipo semiestruturada que, para Manzini (1990/1991, p. 154), “está focalizada em um assunto sobre o qual confeccionamos um roteiro com perguntas principais, complementadas por outras questões inerentes às circunstâncias momentâneas à entrevista". Assim, as questões desse roteiro abrangem características do perfil do discente, suas percepções sobre a diferenciação das habilidades licenciatura e bacharelado, motivação, satisfação/identificação com o curso, investimento na formação, relação entre investimento e desempenho acadêmico, reconhecimento de referencial teórico e análise de apropriação de disciplinas voltadas para a atuação na escolar.

Para a análise dos dados foi utilizada a técnica análise de conteúdo que, para Bardin (2011), consiste em:

...um conjunto de técnicas de análise das comunicações visando a obter, por procedimentos sistemáticos e objetivos de descrição do conteúdo das mensagens, indicadores (quantitativos ou não) que permitam a inferência de conhecimentos relativos às condições de produção/recepção (variáveis inferidas) destas mensagens (BARDIN, 2011, p. 47).

A análise de conteúdo requer a categorização que segundo Bardin (1977, p. 147): “é uma operação de classificação de elementos constitutivos de um conjunto, por diferenciação e, seguidamente, por reagrupamento segundo o género (analogia), com os critérios previamente definidos". Dessa forma, a partir dos dados obtidos nas entrevistas com os professores em formação, foram categorizados perfis para a análise do investimento e desinvestimento de professores em formação.

\section{RESULTADOS E DISCUSSÃO}

Foram convidados para esse estudo alunos do curso de licenciatura em Educação Física, ingressantes dos anos de 2017 e 2018, na Universidade Federal de Viçosa, que atenderam aos critérios definidos na metodologia. Durante a realização do estudo sessenta e dois estudantes estavam matriculados na licenciatura ingressantes do referido biênio. Dezoito estudantes responderam ao convite, assinaram o TCLE e foram entrevistados.

A partir das entrevistas, na fase de pré-análise do conteúdo das falas, para a definição dos perfis, consideramos a motivação para o ingresso no curso de licenciatura em Educação Física, a identificação e satisfação com a área e a perspectiva de atuação. Assim, apresentaremos os perfis de professores de formação dispostos em três categorias, são elas: 1) ser professor!; 2) licenciando ao 
acaso; e 3) Desinvestimento na trajetória formativa docente. Cada perfil, apresenta um conjunto de características que lhe são peculiares, e quanto a algumas variáveis, eles possuem características comuns ou que se relacionam.

Para operacionalizar a descrição dos resultados, os professores em formação foram identificados por códigos alfanuméricos em dois grupos, sendo A17 alunos que ingressaram no curso de licenciatura no ano 2017 e A18 alunos ingressantes no ano de 2018. Dentro de cada grupo, o discente recebeu um número de identificação de forma aleatória, de 1 ao 10 no grupo A17 e de 1 ao 8 , no grupo A18. Portanto para cada entrevistado foi atribuído um código, como por exemplo: A17.1 e A18.1.

\section{Perfil 1: Ser Professor!}

De acordo com as definições para se estabelecer cada perfil, os estudantes que fazem parte deste, em específico, demonstram compreender a especificidade da Licenciatura em Educação Física, bem como uma identificação e satisfação com o curso, demostrando ainda que têm uma boa perspectiva para uma atuação futura, reconhecendo e compreendendo a complexidade da carreira docente. Esse perfil é composto por cinco dos 18 professores em formação entrevistados.

As motivações para o ingresso no curso que envolvem esse perfil perpassam, desde a "realização de um sonho de se tornar professor" (A18.1) à "mudança" que pode ser feita na vida de um aluno a partir da Educação Física. Quando indagado sobre o que levou à escolha do curso de licenciatura em Educação Física, um professor em formação respondeu:

A 18.1: O que me levou a escolher licenciatura em Educação física foi eu ver que através da Educação Física, eu vou conseguir fazer a diferença na vida do meu aluno, que no momento que ele tiver na aula de Educação Física não vai ser só uma obrigação, ele vai sentir prazer em estar ali.(...) Porque na minha aula ele vai saber que vai ter uma boa aula, ...um bom comprometimento com ele ...que comigo ali ele vai aprender muitas coisas. ${ }^{3}$

As afirmações em destaque demostram que a motivação desse discente pela escolha da licenciatura foi pautada em fazer com que seu futuro aluno reconheça a sua aula como uma oportunidade de ter uma experiência de aprendizagem que irá acrescentar à sua formação. Esse estudante demostra que, em suas aulas ele tem a pretensão de criar um ambiente que trabalhe sensações de felicidade e prazer no aluno no momento em que ele participar da aula. É preciso ressaltar que a criação desse ambiente que permita tal sensação não se confunda com uma prática pedagógica esvaziada de sentido e significado, ou seja, sem intencionalidade pedagógica. A

${ }^{3}$ Grifos da autoria 
motivação para contribuir com a formação de maneira ampla se mostrou comum em outros discentes que compõem esse perfil de professores em formação.

Nas perguntas relativas à satisfação e identificação com a área para a formação no ensino superior, todos os entrevistados que estão nesse perfil responderam que estão satisfeitos com a sua escolha pela formação docente e se identificam com a área de atuação da licenciatura. Em relação à perspectiva de atuação futura, houve nuances nas respostas dos estudantes desse perfil. Quando perguntados sobre a percepção de domínio de conhecimentos didático-pedagógicos para uma possível futura atuação, alguns professores em formação afirmaram que sem dúvidas teriam condições de uma intervenção com um amplo domínio didático-pedagógico quanto aos conteúdos e metodologias de ensino da área. Outros, no entanto, responderam que não conseguem afirmar com certeza, como demostra a resposta do aluno a seguir:

A17.1: Então, isso aí pra (sic) mim, eu acho, que é um pouco difícil de determinar, sabe?! Eu acho que são diversos fatores. Depende do ambiente que eu vou trabalhar, da cultura daquela instituição e do nível de ensino. Mas, eu acho que assim, o domínio, eu acho que minha formação vai me possibilitar, mas, o domínio assim do todo, todos os fatores que envolvem tá (sic) ali ministrando aquela aula, fatores como: indisciplina, evasão dos alunos que, infelizmente, é muito frequente nas aulas de Educação Física, isso eu acho, esses fatores vão ser pedras no sapatos, assim, grandes pedras no sapato no enfrentamento da (...) ambientação profissional futura em si, entende?!

A fala desse aluno revela a compreensão da educação em sentido amplo ao demostrar preocupações com fatores como indisciplina, evasão, e particularidades da cultura escolar, o que demostra que esse professor em formação reconhece as potenciais peculiaridades das realidades que ele poderá encontrar. De fato, essa é uma preocupação pertinente ao se compreender a cultura escolar, conforme Barroso (2008, p. 2), como "a cultura organizacional da escola. Neste caso, não falamos da Escola enquanto instituição global, mas sim de cada escola em particular”.

$\mathrm{Na}$ fala desse aluno, demonstra-se, também, preocupação em relação ao momento de transição entre o término da graduação e o início da atuação profissional. A respeito dessa transição de deixar de ser aluno para ser professor, Tardif e Raymond (2000, p.226) ponderam que a socialização profissional do professor iniciante pode incorrer no denominado "choque com a realidade", "choque de transição", ou " choque cultural", que pode gerar uma frustação ou desilusão. É preciso considerar, entretanto, que essa não é uma realidade universalizante, quando a preocupação com a vida de estudante para a vida mais exigente de trabalho pode, também, representar o reconhecimento da complexidade da docência, que demanda, além dos conhecimentos adquiridos ao longo da formação inicial, a noção de que os saberes são constituídos constantemente ao longo de sua atuação profissional. 
As perguntas relativas ao investimento na formação docente também apresentam consonância neste perfil. Notou-se que a maioria (quatro no total de cinco alunos que compõem esse perfil) fez parte do Programa de Iniciação à Docência (PIBID) e citam em suas falas, ao longo da entrevista, a importância desse programa para a sua compreensão da docência.

Para esses alunos, os investimentos feitos na formação estão diretamente ligados à área da docência, pois, demostram interesse por autores clássicos da área da educação como Paulo Freire. Apesar de não ser possível inferir o nível de apropriação desses alunos das leituras feitas do autor citado, ao responderem sobre referências teóricas importantes para a sua formação é possível perceber nas suas falas que existe uma identificação com o autor. Os alunos neste perfil citaram, também, que o contato com essa literatura se deu através de disciplinas específicas do currículo da licenciatura. Outros autores como Suraya Darido, Tarcísio Mauro Vago, Elenor Kunz e Valter Bracht, foram citados como referências importantes para professores em formação neste perfil.

Como forma de perceber o investimento na formação inicial para além das prescrições do currículo, os entrevistados foram indagados sobre as atividades que têm realizado para o preenchimento da carga horária de atividades complementares, que é de $200 \mathrm{~h}$. Sobre estas atividades, Souza, Souza e Bianchi (2015 p.10) argumentam que: "são atividades que visam o enriquecimento do aluno e incorporam ao currículo experiências e vivências acadêmicas dentro e fora da universidade, estimulando a buscado conhecimento, habilidades, competências e atitudes por parte dos estudantes."

Foi possível perceber que os alunos desse perfil investem em atividades complementares em forma de palestras, cursos, programas ligados à área da licenciatura, muitas das quais são fomentadas pela própria instituição. Parece, portanto, haver uma dificuldade em conhecer outras realidades e estabelecer diálogos para além das próprias oportunidades locais mediadas pela própria universidade em que estudam.

Outra questão abordada foi a respeito da definição do que é ser professor na visão dos entrevistados. Dentre as respostas desse perfil, destaca-se:

A 17.1: Ser professor! Eu até emociono, ser professor é algo complexo, eu acho que assim é algo de muita responsabilidade. Acho que um professor é um guia de várias vidas ali. (...) é um mediador do aluno enquanto indivíduo em formação com o meio social, com o mundo em si, sabe?!

A percepção sobre ser professor dentro desse perfil vai além do professor como um mediador do conhecimento. Com frequência foram mencionadas palavras como: responsável, fazer a diferença, dialogar e comprometimento. Além disso, esses discentes demostraram durante toda a 
entrevista que o desejo pela carreira docente está presente há muito tempo na vida deles, como menciona esse professor em formação:

A: 17.1: Licenciatura é, (...) foi assim um sonho de criança que eu tinha, eu falo que desde o sétimo ano eu tive aquela vontade de fazer. Todo mundo perguntava assim: o que você quer ser quando você crescer? E eu falava: - "Professor de Educação Física."

Esse perfil converge com a perspectiva de formação como um processo identitário, que perpassa a motivação para escolher a área de formação em Educação Física, saberes e valores da trajetória de vida que transcendem para o exercício da docência (TARDIF, 2002). Outra característica deste perfil é que, a partir do ingresso no curso, eles tiveram mais clareza sobre a licenciatura em Educação Física e seu papel dentro da escola, sendo pensada de uma forma para além da prática, pensando na formação social, crítica e reflexiva dos alunos. Isso é evidenciado na fala a seguira:

A 18.2: Eu entendi um pouco melhor depois de ter visto a disciplina que fala das abordagens. Então, é muito amplo né, depende muito da abordagem que ele trabalhe. Pode ser mais voltado para o desenvolvimento motor ou ainda de acordo com que eu ainda defendo. Eu ainda tenho muitas coisas para aprender sobre as abordagens, mas com uma visão social.

Dessa forma, em síntese, esse perfil é constituído por alunos que entraram no curso de licenciatura em Educação Física por terem o interesse na carreira docente. Após o ingresso, mantiveram essa pretensão e buscam, por meio da sua trajetória formativa, alcançar o objetivo de ser professor. Estão satisfeitos com as escolhas que vem fazendo e com a estrutura do curso, seja ela física, curricular ou por parte do corpo docente. É importante ressaltar que os alunos mencionaram a carência de cursos complementares específicos para a licenciatura, bem como de disciplinas optativas específicas para a área, mas apontam que as experiências curriculares oferecidas dão subsídios, segundo sua percepção atual, para desempenhar a profissão docente com qualidade e intencionalidade pedagógica.

\section{Perfil 2: Licenciando ao Acaso}

Seguindo o critério estabelecido para constituir cada perfil, os discentes que se encontram no perfil 2 possuem características que apontam que a compreensão da área da licenciatura por eles vem sendo construída após o ingresso no ensino superior. A identificação e satisfação com a escolha do curso se modificaram ao longo da trajetória e, é ao longo da graduação, que estão 
buscando, conhecendo e significando as possibilidades de atuação para a carreira futura. Esse perfil é composto por sete professores em formação.

No momento de escolha do curso de Licenciatura em Educação Física, as motivações desses alunos mostram que alguns optaram pela área sem saber a distinção entre licenciatura e bacharelado, outros por experiências pregressas com os esportes e, também, por causa da diferença da matriz curricular do curso de licenciatura (que tem a carga horaria obrigatória maior e uma carga de disciplinas optativas menor em relação ao bacharelado), o que faz com que o aluno que pretende fazer as duas habilitações otimize o tempo para a conclusão dos dois cursos. Um aluno, ao responder o que motivou a fazer a escolha pela área, argumenta que:

A: 17.3 Quando eu saí da escola, eu sabia que queria fazer Educação Física, mas, eu não sabia a diferença entre licenciatura e bacharel, assim... sabia e não sabia! E, diante a minha nota que não foi muito boa, eu joguei na licenciatura, não pelo fato de desvalorizar a área, até porque eu quero fazer os dois (...) mas, eu não sabia muito bem o que era um ou o que era outro, até por que no nosso ano que mudou, deixou de ser ABI. E então, não tinha muita informação, né?!

A mudança mencionada pelo aluno se trata da extinção do modelo ABI (Área Base de Ingresso) para a entrada na forma específica nas modalidades licenciatura ou bacharelado, que entrou em vigor na universidade foco desse estudo no ano de 2017. É importante observar, também, que as concepções que os alunos trazem até o momento do ingresso no curso, como apreço por determinada modalidade esportiva e afinidade com uma área de conhecimento específica podem moldar sua formação inicial, como afirma Figueiredo (2004):

Queremos dizer que o aluno, com base nas experiências sociais (assumidas, nesse estudo, como as vivências proporcionadas pelas interações que ocorrem nas relações sociais que incluem atividades e experiências corporais e valores a ela atribuídos) realiza ações, interações, hierarquizações, escolhas e, sobretudo, filtra o conhecimento acadêmico que lhe interessa no locus da dinâmica curricular (FIGUEIREDO 2004, P.91).

Com menciona a autora, as experiências pregressas dos ingressantes podem nortear as escolhas deles dentro do curso, sobretudo, em um primeiro momento. Porém, cabe ressaltar que, neste caso em específico, o aluno que ingressa na modalidade de licenciatura tem um maior contato com disciplinas didático-pedagógicas desde o primeiro período. Dessa forma, ele pode vir a compreender o campo de intervenção e as demandas de conhecimentos específicos para a área de escolha e começar um processo de identificação com a mesma, como demostra a resposta do estudante desse perfil: 
A 17.3: Eu me sinto muito feliz daquela escolha imatura que eu fiz ter chegado onde eu estou agora, sabe?! Às vezes eu me pergunto assim: “- E se eu tivesse jogado para o bacharel, será que eu estaria tão feliz assim quanto eu tô (sic) hoje?! Será que eu teria encontrado essa satisfação mesmo daquilo que eu tô (sic) fazendo?! Porque pra (sic) mim é diferente quando eu estou na escola e vou dá aula em uma turma.

Percebe-se que, como mencionado anteriormente, os alunos desse perfil mesmo em um primeiro momento não tendo uma visão abrangente sobre a área que estava ingressando, a partir do início do curso começaram a se identificar com a mesma, descobrindo possibilidades dentro da licenciatura. Um dos fatores apontados pelos estudantes como um momento de maior compreensão do campo de atuação da licenciatura é o contato com a realidade escolar por meio da disciplina de estágio acadêmico supervisionado, além da disciplina de metodologia do ensino da Educação Física.

No modelo que está em vigor na universidade onde este estudo ocorreu, em que a forma de ingresso se dá de forma específica, o primeiro estágio supervisionado acontece no $5^{\circ}$ período e, como afirmam Maffel, Varardi e Fialho (2016), “A consolidação identitária é constituída na experiência com o componente curricular do Estágio Supervisionado, a partir da construção dos saberes para o trabalho e pelas experiências iniciais como professor.' Mas, antes disso, o aluno toma contato com as denominadas "prática de ensino" ${ }^{4}$ desde o primeiro período. Dessa forma, o professor em formação tem no estágio a oportunidade de colocar em prática o aporte teórico conceitual do qual se apropria, além de conhecer a realidade escolar e perceber se ele se identifica com aquele campo de atuação ou não. A respeito da experiência de estágio um aluno menciona que:

A 17.6: Quando eu entrei não me identificava. Mas, depois de um tempo como eu fui entendendo o processo, o que realmente acontece (...), eu achei muito legal. Acho que tendo a experiência de estágio também, é tipo assim, muda sua visão. Então você vê como funciona, e ter a possibilidade de levar o aluno desde da educação infantil até o médio, eu acho isso muito legal.

Como mencionado por esse discente, os estágios acadêmicos fazem a inserção do licenciando no seu futuro ambiente de trabalho. Nesse momento, o professor em formação tem a responsabilidade diante da turma, bem como convive com os conflitos e desafios presentes na realidade escolar. Por outro lado, autores como Cunha (2011), fazem críticas sobre a forma tardia que o aluno em formação de fato é inserido na realidade escolar, inclusive considerando que a carga horária das disciplinas didático-pedagógicas poderia ser maior. Apesar de o currículo que está em

\footnotetext{
${ }^{4}$ As práticas de ensino, contribuem para a construção de uma prática reflexiva ao longo da formação docente. Para Silva (2004, p.61): “A prática de ensino, portanto constitui-se numa oportunidade para os/as discentes-professores/as exercitarem a reflexão superando a dicotomia teoria e pratica. ”
} 
vigor contar com oito práticas de ensino, as falas dos discentes demonstram que as mesmas não têm conseguido consolidar a aproximação dos alunos com a realidade escolar, uma vez que na maioria destas disciplinas, as experiências de ensino se dão em contato com os próprios colegas de turma, $o$ que possibilita um ambiente muito mais previsível e confortável para os professores em formação ministrarem aulas.

Nesse sentido, parece importante propor que as práticas de ensino possam ser operacionalizadas de modo mais próximo com a realidade escolar. Ademais, para minimizar os problemas de um contato "tardio" com o ambiente escolar, o aluno pode investir na sua formação participando de programas, projetos ou outras atividades que tratam da realidade escolar como parte de suas atividades complementares.

Porém, o que se percebe é que as atividades complementares que esses alunos vêm desenvolvendo estão voltadas para áreas que não comtemplam a especificidade da licenciatura, e também estão imersas no próprio âmbito institucional, tal como no perfil anterior. O que agrava a situação é que os alunos relatam, a partir da entrevista, a falta de oferta cursos, localmente, que abordem temáticas voltadas para a Educação Física escolar. Em razão disso, acabam investindo a carga horária de atividades complementares em temas mais voltados ao bacharelado, como em cursos sobre musculação e área fitness.

Os licenciandos também apontam a ausência de oferta de disciplinas optativas voltadas para a licenciatura em Educação Física em sua especificidade. Os alunos destacaram que o perfil de especialidade do corpo docente interfere nessa questão. O fato é que isso demanda atenção, para não incorrer no que Benites, Souza Neto e Hunger (2008) denominaram de "pinceladas" pedagógicas". O termo sugere que os currículos dos cursos de licenciatura, por vezes, têm uma carga horária alta de disciplinas de outras áreas do conhecimento que não é voltada para área didático-pedagógica, com poucas disciplinas nesse sentido.

A pouca oferta de disciplinas optativas voltadas para a licenciatura no departamento de Educação Física, sendo que há um número significativo dessas disciplinas sendo ofertadas voltadas para a área bacharelado, está evidenciada na fala dos entrevistados dos dois perfis aqui apresentados. Este aluno pondera, inclusive, sobre o perfil do corpo docente em suas áreas de especialidade. Essa ausência de optativas para a licenciatura retorna um termo trazido por Benites, Souza Neto e Hunger (2008) denominado de "pinceladas" pedagógicas, no qual eles tratavam que os currículos dos cursos de licenciatura, por vezes, têm uma carga horária de disciplinas de outras áreas dos conhecimentos que não são voltadas para área didático-pedagógica superior no currículo. Portanto, as discussões que deveriam ser priorizadas no currículo da licenciatura apareciam com uma carga horária reduzida. 
Parece haver uma necessidade de equilíbrio da oferta, de disciplinas optativas para ambos os cursos nessa instituição. Claramente isso mobiliza questões administrativas, recursos humanos, dentre outras questões, na busca para contemplar oportunidades de investimento na formação com qualidade aos dois cursos. Então, cabem esforços político-institucionais para se pensar formas de atender as duas habilitações. Na instituição em questão, existe a possibilidade de o professor em formação cursar disciplinas de outros departamentos que dialoguem com a área escolar e com instrumentalização didático-pedagógica, como alternativa de suprir essa lacuna no número de optativas oferecidas pelo departamento. Porém, o que acontece em alguns casos, segundo os alunos, são conflitos de horários entre disciplinas obrigatórias da matriz curricular e a optativa de outro departamento, ou ainda o número de vagas oferecidas pela disciplina não atender a demanda de número de estudantes interessados em cursá-la.

Assim, o perfil em questão tem a peculiaridade dos professores em formação que, mesmo que no momento da inscrição não tinham a clareza do porquê da escolha pela área da licenciatura, conseguiram ao longo da trajetória de formação compreender a área e estão construindo uma identificação com a ideia de tornar-se professor. Dessa forma, é possível perceber que quando o estudante ingressa no curso, engaja-se a fazer do momento de sua formação o melhor possível, à medida que se identifica com a formação, amplia seus recursos para tornar-se um sujeito que no futuro exercerá à docência com responsabilidade pedagógica, intencionalidade e não simplesmente reproduzindo modelos tradicionais de ensino.

E possível perceber, nesse perfil, que os discentes entendem o papel da Educação física escolar e a importância do professor e da escola na formação do aluno, embora seus investimentos se restrinjam às atividades curriculares Um exemplo disso, é que ao citarem os autores que se identificam dentro da área da licenciatura, há um certo ecletismo entre os citados: Marcus Nahas, Suraya Darido, Lino Castellani Filho, Jean Le Boulch. Estas referências, que refletem influências muito diversas, estão associadas ao contato que tiveram em disciplinas específicas ou trabalhos acadêmicos que tiveram que fazer ao longo do curso.

\section{Perfil 3: Desinvestimento na Trajetória Formativa Docente}

Por fim, o último perfil refere-se aos discentes que demostram limitações na compreensão da docência em Educação Física, falta de identificação com a área da licenciatura, porém continuam no curso, mesmo em alguns momentos deixando claro não estarem satisfeitos com a área escolhida. De acordo com os parâmetros adotados para a elaboração dos perfis, esse é o que contém maior discrepância nas respostas dentre seus integrantes, como será demostrado ao longo da discussão referente a esse perfil. Esse perfil é composto por seis professores em formação. 
Inicialmente o que chama a atenção é o fato de a motivação para o ingresso no curso de licenciatura em Educação Física, para esse perfil, de forma recorrente foi baseada no fato de que se viesse a escolher o bacharelado primeiro não faria a licenciatura depois. Como podemos perceber nas repostas a seguir:

A 18.5: então na verdade é, foi porque no início eu queria o bacharelado, mas aí (sic) conversando com alunos que já estavam na educação física eu (...) eles falaram comigo que se eu fizesse bacharel primeiro eu não ia querer fazer a licenciatura depois. Obviamente, isso deu muito certo porque realmente eu não ia querer fazer a licenciatura...

A 18.6: (risos), assim com toda sinceridade do mundo eu escolhi licenciatura, porque eu queria fazer os dois, mas eu achava que se eu fizesse bacharel primeiro eu não ia fazer licenciatura depois. Assim, não é que eu não tenho vocação, mas para determinado nível de ensino eu não tenho paciência, com criança, adolescente. A 17.10: Ah, (sic) eu queria entrar no bacharel, mas, a nota lá era maior, aí eu vim pra cá. (Grifos da autoria)

As respostas citadas mostram que esses alunos, como nos trechos em destaque, tinham como primeira opção o bacharelado. Porém, pela carga horária da licenciatura ou por pretender as duas habilitações em menor tempo, optaram por iniciar pelo curso que não era a sua primeira opção, por uma lógica operacional e que tem relação com o potencial de empregabilidade dos dois campos de atuação.

Além disso, alguns estudantes do perfil 3 demostram um interesse por outros cursos área da saúde ou tem como foco trabalhar com esporte no âmbito do rendimento, preparação física, iniciação esportiva, etc. Esse perfil incorre no risco de não se dedicar a compreender a especificidade da Educação Física escolar, como apontado por Figueiredo (2004, p.89):

A estreita vinculação entre Educação Física e saúde e Educação Física e esporte tem sido, ao longo dos anos, a principal referência dos alunos que ingressam no curso de Educação Física e, ao mesmo tempo, um entrave para que se possa compreender a Educação Física em uma dimensão educacional mais ampla e também suas interfaces com diferentes campos de saberes (FIGUEIREDO, 2004, p.89).

Sendo assim, diferente do perfil anterior em que os alunos foram construindo uma compreensão sobre a área da licenciatura durante a graduação e se identificaram, neste os estudantes não se identificaram com a área escolhida e moldam suas trajetórias formativas investindo em áreas mais distantes da docência, seja por meio de estágios não curriculares em academias e clubes (o que tem implicações legais), cursos, disciplinas optativas voltadas para o bacharelado, bem como outras atividades complementares à formação. Como demostra a fala do estudante a seguir: 
A 18.6: Eu venho preenchendo com atividades do bacharel porque o projeto que eu faço é do bacharel e os cursos que eu faço, acho que teve uma palestra que foi da licenciatura. A maioria dos cursos que eu fiz fora da UFV, fora a semana acadêmica, essas coisas, foram da área do bacharel.

Esse fato revela um distanciamento e pouco investimento do aluno com a área de ingresso, o que é preocupante, pois, mesmo mostrando uma não satisfação e um desinvestimento na área docente, quando foram questionados sobre a percepção de domínio caso viessem a atuar na educação básica, a maioria disse que teria amplo domínio didático-pedagógico quanto aos conteúdos e metodologias. Além disso, esse cenário também pode representar a falta de consciência destes discentes sobre a complexidade da docência em Educação Física na realidade escolar, o que abre possibilidades para que futuros profissionais venham a reproduzir modelos tradicionais de ensino e/ou apresentarem práticas pedagógicas equivocadas.

A falta de investimentos feitos pelo discente pode resultar em compreensão limitada desses alunos a respeito da responsabilidade social de ser professor. Isto porque, a partir do momento em que o aluno não busca, ao longo da sua formação, investir na apropriação de conhecimentos que acrescentem para uma intervenção com intencionalidade pedagógica, preocupada com as diferentes dimensões do conteúdo para subsidiar a prática pedagógica, há o risco iminente desse aluno reproduzir modelos de ensino tradicionais.

Além disso, verifica-se que estes alunos demonstram uma compreensão sobre o papel da Educação Física escolar resumida ao ensino do esporte, preocupada principalmente com aspectos biológicos, questões presentes em modelos de ensino já superados, pelo menos do ponto de vista epistemológico. As respostas dos alunos que compõem esse perfil refletem perspectivas tradicionais e biologicistas para a Educação Física. Um aluno diz que:

A 18.5: Eu vou um pouco mais para questão da saúde renovada e o desenvolvimentismo, eu acredito mais nesses dois sentidos assim. Eu vejo um pouco também, eu acredito um pouco nas abordagens críticas. Mas, na minha visão, pro (sic) momento não é a abordagem crítica que é de preocupar tanto, obviamente estamos voltando para uma era, que temos que preocupar com as abordagens críticas. Mas, eu acredito que tenha mais pessoas sedentárias é (...), mais pessoas que não tenham hábitos saudáveis do que pessoas que precisem dessa abordagem crítica que já é abordada em outras disciplinas como sociologia e filosofia, por exemplo.

Entender que também a Educação Física escolar tem espaço para a abordagem de aspectos biológicos dos esportes, das lutas, da dança, da ginástica e dos jogos e brincadeiras é indiscutível. Porém, não se pode secundarizar a formação crítica do aluno aliada aos conteúdos da Educação Física legitimada em documentos legais e documentos balizadores da educação nacional, bem como 
a perspectiva de formação cidadã que considera princípios éticos e valores previstos na legislação e em todo o avanço epistemológico da Educação e da Educação Física.

A maioria dos alunos desse perfil considera que seu desempenho acadêmico é satisfatório em relação ao investimento em tempo de estudo, presença em aulas e cumprimento das atividades. Como já mencionado, muitos dedicam seus investimentos a áreas esportivas e, em suas horas de atividades completares, os alunos mencionam participação em projetos, grupos de estudos e pesquisa voltados para o campo de conhecimentos e atuação do bacharel. Porém, deixam claro que não têm como foco a área da licenciatura e, por isso, buscam outros caminhos dentro da sua formação inicial, mas, não descartam a possibilidade de atuar na escola. Isso parece demonstrar uma preocupação com empregabilidade, ou seja, mercado de trabalho.

É preciso se atentar para esse fato uma vez que os investimentos feitos nas atividades complementares estão distantes da área escolar. Quando citam os autores que mais se identificam, as referências mencionadas por esse perfil foram: Vygotsky, Piaget, Freud. Alguns alunos responderam não se lembrar nenhum autor da área e também não se identificarem com nenhum autor. Os autores mencionados transitam entre a perspectiva interacionista e psicogenética do jogo e do brincar, a compreensão de fases de desenvolvimento humano, etc. Além disso a compressão do papel da Educação Física escolar na visão desse perfil é, predominantemente, voltada para os aspectos biológicos. Caso venham a atuar no ambiente escolar esses discentes parecem sinalizar que suas práticas pedagógicas não priorizarão a visão de formação cidadã. Se considerarmos a análise de Machado et al. (2010) sobre o desinvestimento pedagógico como um estado do professor na atuação profissional, há o risco iminente que essa postura diante da formação leve a práticas esvaziadas de sentido pedagógico ou reduzidas à função de administrador de materiais, o que é grave.

\section{CONSIDERAÇÕES FINAIS}

Embora para efeito metodológico do estudo tenham sido caracterizados perfis conforme a motivação para ingresso, satisfação com a escolha do curso e perspectiva de futura atuação, esses perfís não são estanques. Eles têm entre si interlocuções. Sendo assim, não se pretende rotular, enquadrar as pessoas, com uma identidade fixa. O exercício científico feito neste estudo produziu um mapeamento de características de professores em formação, entretanto, os sujeitos são históricos e a realidade é dinâmica.

Em suma, os perfis 1 e 2 demostram compreensão ampla da área da licenciatura, entendendo o papel da Educação Física escolar e de ser professor como contribuição para a formação humana e cidadã. Apesar disso, seus investimentos na formação, assim como é comum a todos os perfis, 
demostram uma dependência do currículo. Apesar disso, sobretudo o perfil 1, realiza-se investimentos voltados para a constituição dos seus saberes próprios e específicos para o exercício da docência.

Em geral, em todos os perfis, professores em formação demonstram poucas iniciativas de formação complementar sistematizadas, que busquem complementar o currículo institucional ou suprir lacunas, como demostrado nas falas dos próprios estudantes. Portanto, notou-se a necessidade de oportunizar mais oportunidades para a reflexividade sobre o investimento na formação docente por vias institucionais.

Espera-se do professor em formação um protagonismo em sua formação, que suas escolhas sejam pensadas em fazer da sua trajetória formativa um momento de constituição de saberes e constituição de si como sujeito que possam trazer sentido para sua futura atuação. Não foi possível inferir, através do instrumento desse estudo, o nível de profundidade de leitura e de apropriação de conhecimentos teórico-metodológicos por parte dos alunos, mas, foi possível perceber algum reconhecimento do campo epistemológico da área, sobretudo pelos perfis "ser professor!" e "licenciando ao acaso".

Os dados encontrados no perfil "a desinvestimento na trajetória formativa docente" demostram características preocupantes, uma vez que mostram que o professor em formação não perspectiva a área de modo abrangente, mesmo já tendo cursado a maior parte das disciplinas didático-pedagógicas que o curso prevê. Ao mesmo tempo, não descartam a possibilidade de atuar na área, mesmo insatisfeitos e não se identificando com a profissão. Além disso, o perfil 3 traz em suas respostas ideias de Educação Física escolar amparadas em práticas pedagógicas tradicionais do ponto de vista epistemológico. Os investimentos deste perfil se distanciam da realidade escolar, ou seja, não que esses alunos não estejam investindo em sua formação, porém seus investimentos não têm relação direta com a atuação com a Educação Física escolar em suas especificidades.

Como citado nesse estudo, Machado et al. (2010) analisaram o desinvestimento do professor já em atuação, mostrando que durante a atuação o professor, por diversos fatores, não exerce mais sua função docente com intencionalidade pedagógica e a questão da formação emerge naquela discussão em relação às influências que a formação têm na constituição dos saberes e prática docente. Com os resultados apresentados até aqui, sobretudo no perfil 3, é possível inferir que o desinvestimento pode ter início na graduação, à medida que o estudante distancia seus investimentos da carreira docente, assumindo o risco de atuar sem o aprofundamento, comprometimento e responsabilidade que a profissão docente exige.

Nota-se, a julgar pelos perfis 1 e 2, que o ingresso em formação especifica, como acontece na UFV desde de 2017, vem repercutindo para os professores em formação, uma vez que eles 
reconhecem terem um número de disciplinas que promovem a reflexão sobre o ambiente escolar e ser professor, o que poderia ser problemático em relação a um retorno ao $\mathrm{ABI}$, como proposto na Resolução 06/2018.

Assim, ao considerar a voz de futuros professores, a produção cientifica se estabelece como um canal de escuta destes atores. Pois, a partir das ideais apresentadas por eles, é possível pensar em melhorias para os currículos de formação, considerando a perspectiva do licenciando sobre sua trajetória docente. Além disso, segundo os resultados discutidos, a habilitação específica pode contribuir para que cada vez menos se tenha a reprodução de modelos pedagógicos tradicionais dentro da Educação Física escolar em razão de pinceladas pedagógicas nos currículos.

Os dados permitem inferir que os caminhos formativos de futuros professores de Educação Física demandam políticas públicas e institucionais para o fortalecimento das licenciaturas em suas possibilidades de ensino (como a maior oferta de disciplinas optativas específicas demandadas pelos alunos, por exemplo); pesquisa (com o apoio das agências de fomento às pesquisas educacionais e sobre formação); e de extensão (com programas e projetos voltados para a experiência e reflexão sobre a docência, como se destaca no perfil 1).

Portanto, é preciso ampliar as oportunidades de reflexividade para os discentes por vias institucionais e, também, aprofundar uma formação política que permita o professor em formação reconhecer e compreender a importância do seu protagonismo na sua formação frente à responsabilidade da profissão docente. É preciso sinalizar como possibilidade para estudos futuros a realização de pesquisas longitudinais, que acompanhem a trajetória de formação e atuação de professores de Educação Física. Esse tipo de estudo pode contribuir para a relação entre continuidades e descontinuidades de investimentos e desinvestimentos na formação e na atuação.

\section{REFERÊNCIAS}

BARDIN, Laurence. Análise de conteúdo. Lisboa: Edições 70, 1977.

BARDIN, Laurence. Análise de conteúdo. São Paulo: Edições 70, 2011.

BARROSO, João. Cultura, cultura escolar, cultura de escola. Princípios Gerais da Administração Escolar, v. 1, 2013. Disponível em:

https://acervodigital.unesp.br/bitstream/123456789/65262/1/u1_d26_v1_t06.pdf. Acesso: 23 jun. 2020.

BENITES, Larissa Cerignoni; SOUZA NETO, Samuel de; HUNGER, Dagmar. O processo de constituição histórica das diretrizes curriculares na formação de professores de Educação Física. Educação e Pesquisa, [S.L.], v. 34, n. 2, p. 343-360, ago. 2008. Disponível em:

http://www.scielo.br/scielo.php?script=sci_arttext\&pid=S1517-97022008000200009\&lng=en\&nrm=iso. Acesso em: 05 nov. 2019.

BRASIL, Conselho Federal de Educação. Resolução nº. 03 de 16 de junho de 1987. 
BRASIL. Resolução CNE/CES n ${ }^{\circ}$ 6, de 18 de dezembro de 2018. Diretrizes Curriculares Nacionais dos Cursos de Graduação em Educação Física. Diário Oficial da União nº 243, de 19 de dezembro de 2018 Seção 1- pág. 48.

CUNHA, Jose Jailton da Formação do professor de Educação Física: coerências e incoerências. 2011. Dissertação de Mestrado. Faculdade de Educação. UNOESTE, Presidente Prudente, 2011.

FARIA, Bruno Almeida; BRACHT, Valter; MACHADO, Thiago Silva. Inovação pedagógia na educação física: o que aprender com práticas bem sucedidas. Ágora para la Educación Física y el Deporte, Valladolid, v. 12, p. 11-28, 2010. Disponível em: https://dialnet.unirioja.es/servlet/articulo?codigo=3217498. Acesso em: 11 jun. 2020.

FIGUEIREDO, Zenolia Christina Campos. Formação docente em Educação Física: experiências sociais e relação com o saber. Movimento (ESEFID/UFRGS), Porto Alegre, v. 10, n. 1, p. 89-111, dez. 2004. Disponível em: https://seer.ufrgs.br/Movimento/article/view/2395. Acesso em: 20 nov. 2019.

MACHADO, Thiago da Silva; BRACHT, Valter; FARIA, Bruno de Almeida; MORAES, Claudia; ALMEIDA, Ueberson; ALMEIDA, Felipe Quintão. As Práticas De Desinvestimento Pedagógico Na Educação Física Escolar. Movimento (ESEFID/UFRGS), Porto Alegre, v. 16, n. 2, p. 129-147, dez. 2009. Disponível em: https://seer.ufrgs.br/Movimento/article/view/1049. Acesso em: 07 mai. 2020.

MAFFEI, Wiler Soares; VERARDI, Carlos Eduardo Lopes; PESSÔA FILHO, Dalton Muller Formação inicial do professor de Educação Física: produções acadêmicas entre 2005 - 2014. Motrivivência, Florianópolis, v. 28, n. 49, p. 146-163, nov. 2016. Disponível em:

https://periodicos.ufsc.br/index.php/motrivivencia/article/view/21758042.2016v28n49p146. Acesso em: 29 nov. 2019.

MANZINI, Eduardo José. A entrevista na pesquisa social. Didática, São Paulo, v. 26/27, p. 149-158, 1990/1991.

SAVIANI, Demerval. Formação de Professores: aspectos históricos e teóricos do problema no contexto brasileiro. Revista Brasileira de Educação, Rio de Janeiro, v. 14, n. 40, p. 142-155, jan./abr. 2009. Disponível em: http://www.scielo.br/pdf/rbedu/v14n40/v14n40a12.pdf . Acesso em: 13 out. 2019.

SILVA, Wilson Rufino. A prática de ensino na formação docente: conversando com os/as discentesprofessore/as. Recife: O Autor, 2005. 135 Folhas. Disponível em:

https://repositorio.ufpe.br/handle/123456789/4659. Acesso em 01 jun. 2020

SOUZA, Lucena; SOUZA, Juliana Tarrago; BIANCHI, Marcia. Atividades complementares no curso de ciências contábeis da universidade federal do rio grande do sul: habilidades e competências. Trabalho de Conclusão de Curso, 2015, Departamento de Ciências Contábeis e Atuariais da Faculdade de Ciências Econômicas da Universidade Federal do Rio Grande do Sul (UFRGS). Disponível em:

https://www.lume.ufrgs.br/bitstream/handle/10183/140637/000989973.pdf?sequence=1 Acesso: $30 \mathrm{abr}$. 2020 .

TARDIF, Maurice; RAYMOND, Danielle. Saberes, tempo e aprendizagem do trabalho no magistério. Educação \& Sociedade, Campinas, v. 21, n. 73, p. 209-244, dez. 2000.

TARDIF, Maurice. Saberes Docentes e Formação Profissional. $5^{\circ}$ Edição. Petrópolis, RJ. Vozes 2002.

ZANATTA, Jacir Afonsa; COSTA, Mauricio Luis. Algumas reflexões sobre a pesquisa qualitativa nas ciências sociais. Estud. pesqui. psicol., Rio de Janeiro, v. 12, n. 2, p. 344-359, ago. 2012. Disponível em: http://pepsic.bvsalud.org/scielo.php?script=sci_arttext\&pid=S180842812012000200002. Acesso em: 13 jun. 2019. 


\section{NOTAS DE AUTOR}

\section{AGRADECIMENTOS}

Agradecemos aos membros do Laboratório de Estudo e Pesquisa em Educação Física Escola e Sociedade (LEPEFES) da Universidade Federal de Viçosa.

CONTRIBUIÇÃO DE AUTORIA - Não se aplica.

FINANCIAMENTO - Não se aplica.

CONSENTIMENTO DE USO DE IMAGEM - Não se aplica.

\section{APROVAÇÃO DE COMITÊ DE ÉTICA EM PESQUISA}

O estudo foi submetido e aprovado como projeto de pesquisa ao Comitê de Ética e Pesquisa da Universidade Federal Viçosa em 2019, sob o número de parecer 3.797.206. Os procedimentos éticos foram realizados de acordo com a resolução 466/2012 do de Conselho Nacional de Saúde. Também se reafirma a conformidade com a Resolução CNS nº 510 de 2016 (Normas aplicáveis a pesquisas em Ciências Humanas e Sociais).

CONFLITO DE INTERESSES - Não se aplica.

\section{LICENÇA DE USO}

Os autores cedem à Motrivivência - ISSN 2175-8042 os direitos exclusivos de primeira publicação, com o trabalho simultaneamente licenciado sob a Licença Creative Commons Attribution Non-Comercial ShareAlike (CC BY-NC SA) 4.0 International. Esta licença permite que terceiros remixem, adaptem e criem a partir do trabalho publicado, desde que para fins não comerciais, atribuindo o devido crédito de autoria e publicação inicial neste periódico desde que adotem a mesma licença, compartilhar igual. Os autores têm autorização para assumir contratos adicionais separadamente, para distribuição não exclusiva da versão do trabalho publicada neste periódico (ex.: publicar em repositório institucional, em site pessoal, publicar uma tradução, ou como capítulo de livro), com reconhecimento de autoria e publicação inicial neste periódico, desde que para fins não comerciais e compartilhar com a mesma licença.

\section{PUBLISHER}

Universidade Federal de Santa Catarina. Programa de Pós-Graduação em Educação Física. LaboMídia Laboratório e Observatório da Mídia Esportiva. Publicado no Portal de Periódicos UFSC. As ideias expressadas neste artigo são de responsabilidade de seus autores, não representando, necessariamente, a opinião dos editores ou da universidade.

\section{EDITORES}

Mauricio Roberto da Silva, Giovani De Lorenzi Pires, Rogério Santos Pereira.

\section{EDITORA DE SEÇÃO}

Bianca Natália Poffo.

\section{REVISÃO DO MANUSCRITO E METADADOS}

João Caetano Prates Rocha; Keli Barreto Santos.

\section{HISTÓRICO}

Recebido em: 17 de setembro de 2020.

Aprovado em: 16 de novembro de 2020. 